\title{
RESEARCH IMPACT OF CONSERVING LARGE MILITARY VEHICLES THROUGH A SUSTAINABLE METHODOLOGY
}

\author{
A. SAEED ${ }^{1}$, Z.A. KHAN ${ }^{1}$, H. NAZIR ${ }^{1}$, M. HADFIELD ${ }^{1} \&$ R. SMITH ${ }^{2}$ \\ ${ }^{1}$ NanoCorr, Energy and Modelling Research Group, Bournemouth University, UK. \\ ${ }^{2}$ The Tank Museum at Bovington, UK.
}

\begin{abstract}
The objective of this article is to present the research impact, significance and reach made for British military heritage. An effective knowledge exchange model is being developed in terms of substantial contribution to the identification, measurement, analysis, prediction and condition-monitoring of structural failures within military tanks with enormous societal and economic impact. This is the first evidence-based research carried out in this field and is directly linked to the development of a new conservation facility, further research and grants.

Keywords: corrosion, impact, large vehicles, sustainable.
\end{abstract}

\section{INTRODUCTION}

With the imminent centenary of the end of World War I and the passing of the generation that fought in World War II, the conservation of significantly deteriorating military tanks, which are one of the classic examples of British engineering heritage, has taken on a new prominence. To implement a framework that is able to oversee and as a result retard structural deterioration, a research collaboration was established between The Tank Museum at Bovington and Bournemouth University. During this project, a process of developing a sustainable framework to slow down structural degradation through corrosion and wear begun with the objectives to (a) identify, measure, analyse, predict and retard corrosion failures; (b) develop a condition-monitoring framework based upon advanced sensors; and (c) commence an improved approach to safeguard and withstand military tanks stationed inside and outside the shelters in The Tank Museum cost effectively.

This article aims to elaborate on the overall research significance, contributions to the British military heritage and stakeholder and societal impact [1-17].

\section{STRUCTURAL FAILURES MITIGATION PROGRAMME}

Research began with a specific aim to address the increasing problems of structural deterioration due to corrosion and component failures in the vehicles at The Tank Museum. This research has started

- The development of a model to identify, measure, analyse, predict and retard structural failures

- The development of an in situ condition-monitoring framework to identify and monitor corrosion in the structures

- The initiation of an optimized approach to protect and sustain military tanks stationed inside and outside the shelters

This paper is part of the Proceedings of the 3rd International Conference on Defence Sites: Heritage and Future (Defence Heritage 2016)

www.witconferences.com
} 


\subsection{Structural failures}

Research conducted with The Tank Museum has presented many challenges as the literature and knowledge of the materials/components utilized, design process and manufacturing techniques were missing and incomplete. The history of the service life incorporating operational and environmental conditions under which the vehicles operated previously is incomplete and in many cases unknown. Extensive experimental research to identify, measure, analyse, predict and monitor structural failures was conducted on 20 vehicles. This research provided important information on the severity of corrosion problem in vehicles as shown in Fig. 1. Other structural failures associated with corrosion directly and/or indirectly were also identified, as shown in Fig. 2. Through advanced material characterization techniques, the material composition, which was processed in World War II, was obtained; this was followed by extensive research programme in corrosion failure analysis [1, 4].

\subsection{Environmental monitoring}

Relative-humidity and temperature variations strongly influence structural deterioration due to corrosion. It was identified in this research that variations in the relative humidity and temperatures were not viable to keep the tanks safe against structural failures. As a result, the monitoring of relative humidity and temperatures has started at ten different locations, and variations are now constantly monitored. The monitoring mechanisms of such parameters and as a result keeping the variations to a minimum will help towards sustainable conservation of the vehicles [2].

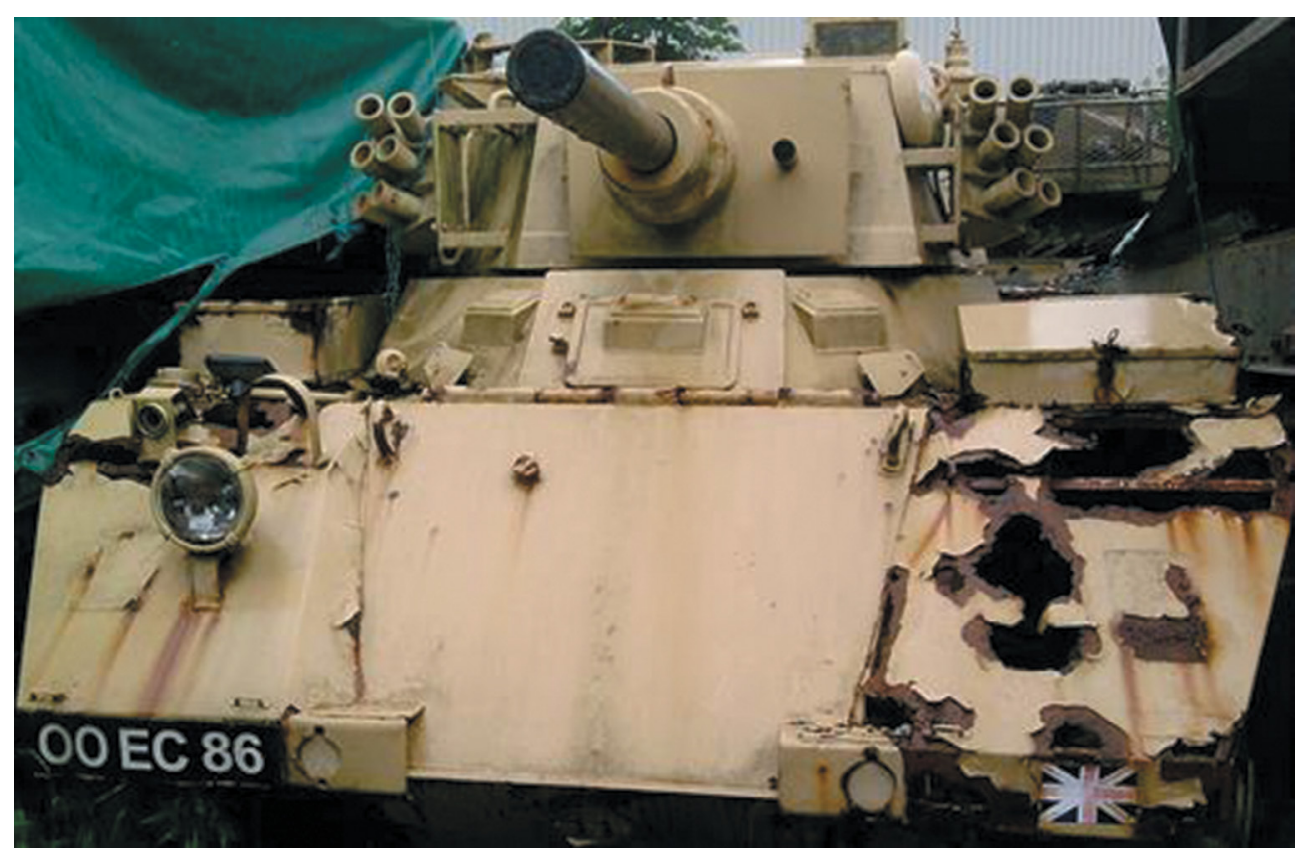

Figure 1: Corrosion problems in Saladin armoured car. 

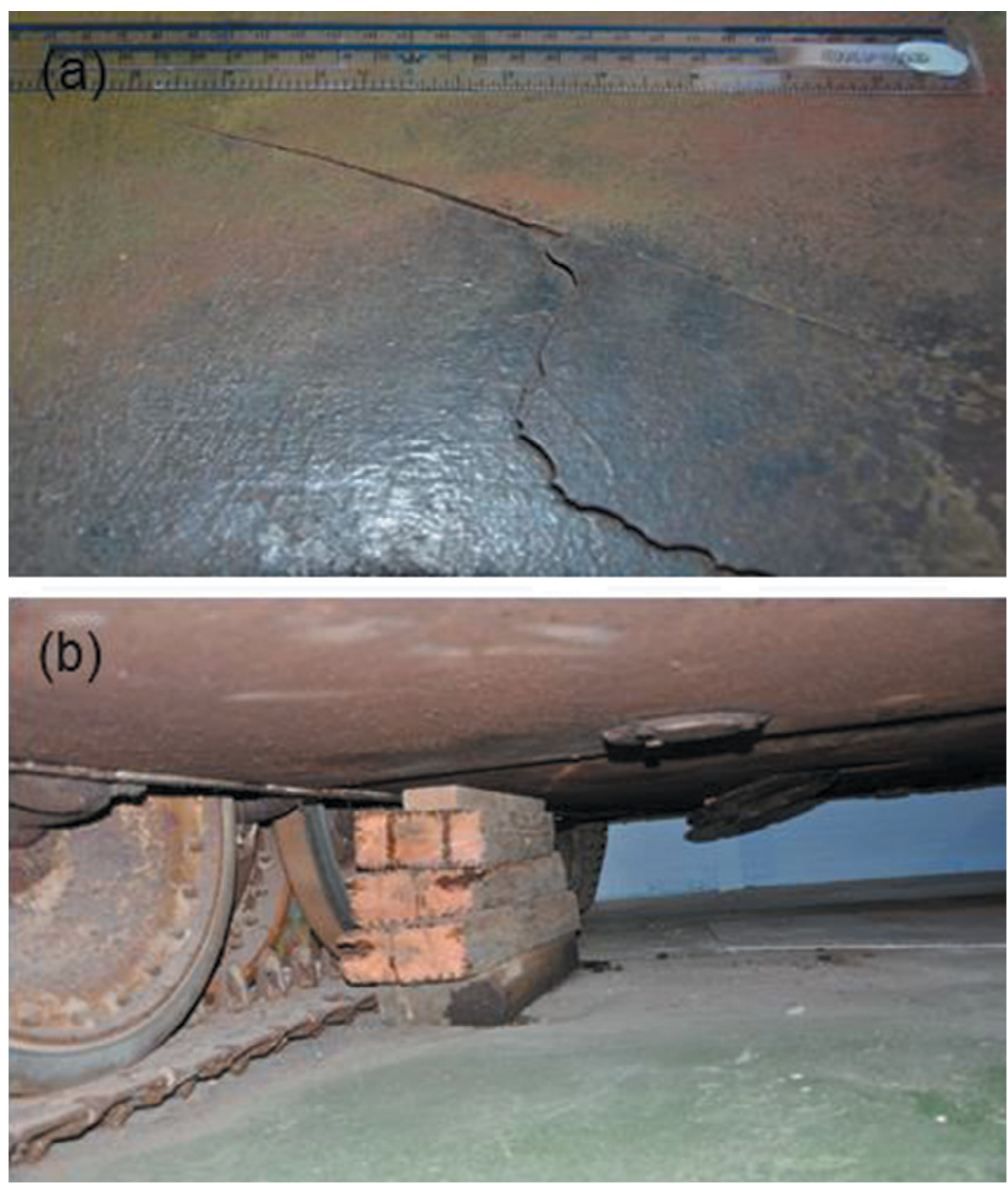

Figure 2: (a) Crack propagation in Mark II hull. (b) Suspension failure in Jadgpanther, Sdkfz $173[18]$.

\subsection{Corrosion monitoring}

An advanced method to condition-monitor structural failures due to corrosion has been put in place on the two tanks. This methodology provides the opportunity to collect data in real time when corrosion starts to occur on the tank surfaces. This is one of the most innovative methodologies to oversee corrosion initiation and propagation. The Tank Museum at 
Bovington is believed to be the only museum in the world with condition-monitoring system on their vehicles. The data composed through this framework are very important in terms of providing a sustainable methodology to conserve military tanks' cost-effective methodology.

\subsection{Corrosion modelling}

Corrosion data obtained through the condition-monitoring technique has been utilized to simulate corrosion tests experimentally for the purpose of life expectancy programme. These experimental results have been utilized to model corrosion in certain environments. Data from the live corrosion monitoring and experimental results have been compiled, and the process of designing an empirical model to develop a life expectancy and longevity programme for military tanks has started $[11,16]$.

\section{RESEARCH IMPACT}

\subsection{Knowledge dissemination}

Research with The Tank Museum has attracted substantial interest from the wider research community. Table 1 provides some of our most read and cited papers. Three out of four papers have made it to the most read articles in the Journal of Adhesion Science and

Table 1: List of the most downloaded published articles in year 2015.

\begin{tabular}{|c|c|c|c|}
\hline Sl no & Article title & Citations & $\begin{array}{l}\text { Publication } \\
\text { year }\end{array}$ \\
\hline
\end{tabular}

$1 \quad$ Modelling of metal-coating delamination 9 2015 incorporating variable environmental parameters

2 Optimisation of interface roughness and coating 8 2015 thickness to maximise coating - substrate adhesion-a failure prediction and reliability assessment modelling

3 A unified mathematical modelling and simulation for cathodic blistering mechanism incorporating diffusion and fracture mechanics concepts

4 A holistic mathematical modelling and simulation for cathodic delamination mechanism - a novel and an efficient approach

5 Material characterization and real-time wear evaluation of pistons and cylinder liners of the Tiger 131 military tank

6 Corrosion damage analysis and material characterization of Sherman and Centaur-the historic military tanks

$7 \quad$ Non-destructive material characterisation and material loss evaluation in large historic military vehicles 
Technology (JAST) (Taylors \& Francis). One of our papers [10] is the most read (article read number $=1,948)$, making it to the top of the list in just a few months, and has retained its top position even after 11 months. The other two articles $[12,19]$ are at 8th and 11th positions, with 658 and 555 reads, respectively, and have retained their position for the past 6-8 months.

Another article [11] that is open access in JAST is also contributing a lot in the coating durability field, which can be seen in terms of citations. The article has been cited five times in just four months of its publication (11 August 2015). This research is linked with successfully completed research in collaboration with The Tank Museum.

\subsection{Impact on museums}

This research has worked as a connection among the museums in the UK and Europe. Informed research activity with The Tank Museum has resulted in The National Museum sector steering committee meetings and regular national and international museum-level meetings including at Bournemouth University, to define good practice of large object preservation within various environments and operating conditions to maximize public value. Research with The Tank Museum has attracted significant public interest, and a successful EU Museums Conference on 2 July 2012 at Bournemouth University is one of the examples of evidence of impact.

\subsection{Conservation centre}

Recommendation from this research has helped towards securing $£ 2.5$ million Heritage Lottery Fund to build a new vehicle conservation centre in The Tank Museum as shown in Fig. 3. The new facility $\left(3,700 \mathrm{~m}^{2}\right)$ can accommodate most of the museum tanks so that they can be protected against environmental damage and also provides the opportunity for the ongoing volunteer-led conservation and preservation programme aimed at diminishing corrosion failures in a non-invasive and cost-effective way.

\subsection{Societal impact}

The Tank Museum attracts approximately 200,000 visitors every year. This research aims to extend the life expectancy of the military heritage in The Tank Museum at Bovington. This will enable the British public and future generations to enjoy the British engineering legacy from the Great Wars for a longer time.

During the course of this project, research work was conducted on Tiger 1 main battle tank [1]. This created an important public engagement through YouTube, which has thus far crossed one million views. This is a clear indication of British public interaction with our research through The Tank Museum collection.

\subsubsection{STEAM school programme}

One of the most exciting public engagements due to this research was the working together of Bournemouth University, The Tank Museum and Harewood College to arrange the Science, Technology, Engineering, Arts and Maths programme (STEAM) for secondary school children in January every year. Children from secondary schools across Dorset County in the 


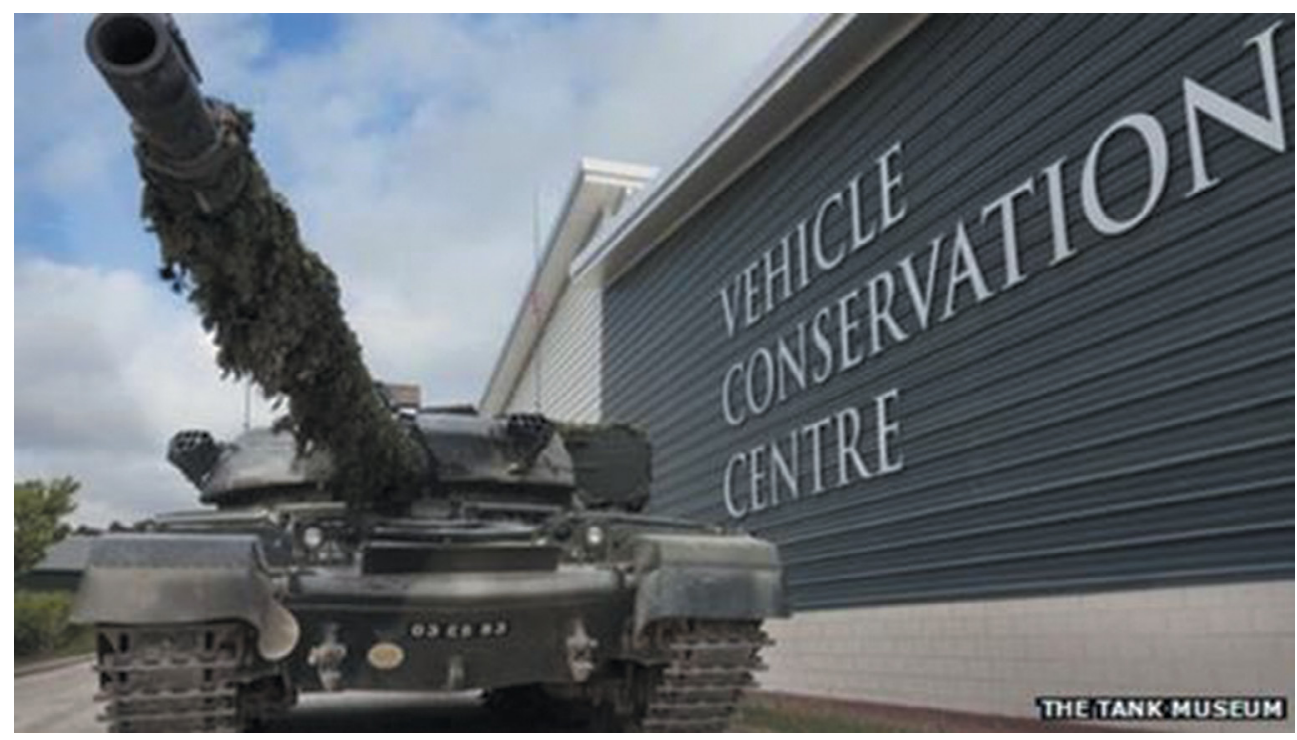

Figure 3: Building of the new conservation facility at The Tank Museum. Image courtesy of The Tank Museum.

UK are divided into teams to compete against each other to successfully negotiate an obstacle course using Lego tanks that they design and build.

This practical, hands-on competition provides an opportunity to the secondary school pupils to participate in small engineering projects.

\subsubsection{Purbeck at War and science school club}

The Purbeck at War project is run by Purbeck School and is funded by the Heritage Lottery Fund. This project aims to help young people better understand the effect of war on the local landscape and society. As part of the project, pupils from local primary schools visit The Tank Museum for a day of activities themed around World War I.

The Tank Museum provides the necessary support to Purbeck School pupils to discover the remains of trenches in the north of Bovington that were originally dug for the first tank crews to practice. School pupils use global positioning system devices to sketch the trench systems.

The Tank Museum provides the opportunity to the star pupils of the 'Science after School Club' of Lulworth \& Winfrith Primary School to float a tank, built a projectile launcher and construct a bridge to support the weight of a remote control vehicle. This helps motivate pupils to multiply their knowledge of science and engineering. This activity provides not only a knowledge base for children but also an opportunity to make new friends and learn teamwork skills.

\section{CONCLUSIONS}

This article has elaborated on the research impact of the sustainable methodology for conserving military tanks in the museum environment. Advanced research methodologies were deployed during this research to identify, measure, analyse, predict and monitor structural failures. This article has contributed significantly to research through the distribution of journal and conference publications. 
Through an effective knowledge exchange programme, general public engagement has been attracted, the dissemination of the research knowledge has started to the future generations, accessing future funding and new opportunities have been pursued; thus through advanced research informed decisions can be made to preserve British engineering heritage against structural failures sustainably.

\section{REFERENCES}

[1] Saeed, A., Khan, Z.A., Hadfield, M. \& Davies, S., Material characterization and realtime wear evaluation of pistons and cylinder liners of the Tiger 131 military tank. Tribology Transactions, 56, pp. 637-644, 2013. DOI: 10.1080/10402004.2013.771416

[2] Saeed, A., Khan, Z.A. \& Montgomery, E., Corrosion damage analysis and material characterization of Sherman and Centaur - the historic military tanks. Materials Performance and Characterization, 2, pp. 30-44, 6 February 2013. DOI: 10.1520/ MPC20120016

[3] Wilton-Smith, K., Khan, Z.A., Saeed, A. \& Hadfield, M., Accelerated corrosion tests of waste-gated turbocharger's adjustable and fixed end links. Presented at the International Conference on High Performance and Optimum Design of Structures and Materials, 9-11 June 2014, Ostend, Belgium.

[4] Saeed, A., Khan, Z.A., Garland, N. \& Smith, R., Material characterisation to understand various modes of corrosion failures in large military vehicles of historical importance. Presented at the Fifth International Conference on Computational Methods and Experiments in Materials Characterisation, 13-15 June 2011, Kos, Greece.

[5] Saeed, A., Khan, Z.A., Clark, M., Nel, N. \& Smith, R., Non-destructive material characterisation and material loss evaluation in large historic military vehicles. Insight: NonDestructive Testing and Condition Monitoring, 53, pp. 382-386, 2011. DOI: 10.1784/ insi.2011.53.7.382

[6] Khan, Z.A., Grover, M. \& Nazir, M.H., The implications of wet and dry turning on the surface quality of EN8 steel. Transactions on Engineering \& Technologies, G. Yang, S. Ao, L. Gelman, editors. Springer: Dordrecht, pp. 413-423, 2015.

[7] Khan, Z.A., Pashaei, P., Bajwa, R.S., Nazir, M.H. \& Camak, M., Fabrication and characterisation of electrodeposited and magnetron sputtered thin films. International Journal of Computational Methods \& Experimental Measurements, 3(2), pp. 165-174. DOI: 10.2495/CMEM-V3-N2-165-174

[8] Nazir, M., Khan, Z.A. \& Stokes, K., A unified mathematical modelling and simulation for cathodic blistering mechanism incorporating diffusion and fracture mechanics concepts. Journal of Adhesion Science and Technology, 29, pp. 1200-1228, 2015. DOI: 10.1080/01694243.2015.1022496

[9] Nazir, M., Khan, Z.A. \& Stokes, K., Optimisation of interface roughness and coating thickness to maximise coating - substrate adhesion - a failure prediction and reliability assessment modelling. Journal of Adhesion Science and Technology, 29, pp. 14151445, 2015. DOI: 10.1080/01694243.2015.1026870

[10] Nazir, M.H., Khan, Z. \& Stokes, K., Modelling of metal-coating delamination incorporating variable environmental parameters. Journal of Adhesion Science and Technology, 29, pp. 392-423, 2014. DOI: 10.1080/01694243.2014.990200

[11] Nazir, M.H., Khan, Z.A. \& Stokes, K., A holistic mathematical modelling and simulation for cathodic delamination mechanism - a novel and an efficient approach. Journal of Adhesion Science and Technology, 29(22), pp. 2475-2513, 2015. DOI: 10.1080/01694243.2015.1071023 
[12] Saeed, A., Khan, Z. \& Nazir, M., An optimised approach of protecting and sustaining large vehicle system. Sustainability, 7, p. 15825, 2015. DOI: 10.3390/su71215825

[13] Khan, Z.A., Hadfield, M., Tobe, S. \& Wang, Y., Ceramic rolling elements with ring crack defects - a residual stress approach. Materials Science and Engineering: A, 404, pp. 221-226, 2005. DOI: 10.1016/j.msea.2005.05.087

[14] Khan, Z.A. \& Hadfield, M., Manufacturing induced residual stress influence on the rolling contact fatigue life performance of lubricated silicon nitride bearing materials. Materials \& Design, 28, pp. 2688-2693, 2007. DOI: 10.1016/j.matdes.2006.10.003

[15] Khan, Z.A., Hadfield, M. \& Wang, Y., Pressurised chamber design for conducting rolling contact experiments with liquid refrigerant lubrication. Materials and Design, 26, pp. 680-689, 2005. DOI: 10.1016/j.matdes.2004.08.006

[16] Nazir, M., Khan, Z., Saeed, A. \& Stokes, K., Modelling the effect of residual and diffusion induced stresses on corrosion at the interface of coating and substrate. Corrosion Journal, 72(4), pp. 500-517, 2016. DOI: 10.5006/1804

[17] Ramesh, C.S., Adarsha, H., Pramod, S. \& Khan, Z., Tribological characteristics of innovative Al6061-carbon fiber rod metal matrix composites. Materials and Design, 50, pp. 597-605, 2013. DOI: 10.1016/j.matdes.2013.03.031

[18] Saeed, A., Sustainable Methodology of Conserving Historic Military Vehicles, Bournemouth University, 2013, http://eprints.bournemouth.ac.uk/20975/ ID code: 20975.

[19] Nazir, M.H., Khan, Z.A., Saeed, A. \& Stokes, K., A model for cathodic blister growth in coating degradation using mesomechanics approach. Materials and Corrosion, 2015. DOI: 10.1002/maco.201508562. http://onlinelibrary.wiley.com/doi/10.1002/ maco.201508562/epdf 